\title{
PAVIMENTO ESTRIADO EM ROCHAS DO SUBGRUPO ITARARÉ AO LONGO DO RIO PIRITUBINHA, SUL DO ESTADO DE SÃO PAULO
}

\author{
MARIA RITA CAETANO-CHANG*, JOSÉ PEDRO DE OLIVEIRA** e \\ JOSELI MARIA PIRANHA BRIGHETTI***
}

INTRODUÇÃO Evidências diretas da atividade glacial nos sedimentos do Subgrupo Itararé (Carbonífero SuperiorPermiano Inferior, Bacia do Paraná) são relativamente escassas, especialmente as indicativas do sentido de fluxo das geleiras. Dados esparsos estão registrados na literatura (Almeida 1948, Amaral 1965,Bigarella«ífl/. 1967, Roçha-Cainpos et al. 1968, 1969, 1977, 1988, Machado 1989) sobre a ocorrência de feições erosivas devidas à glaciação gondwânica na Bacia do Paraná, tais como pavimentes estriados, marcas crescentes em seixos e pavimentes e rochas moutonnée. Além disso, é de conhecimento no meio geológico nacional que estes patrimônios geológicos têm sido freqüentemente delapidados pelo homem, caso, por exemplo, do famoso pavimento estriado de Wittmarsum, no Estado do Paraná, esculpido em arenitos da Formação Furnas (Devoniano, Bacia do Paraná). Outro exemplo de destruição é o da famosa rocha moutonnée de Salto (SP), feição esculpida em granito do embasamento.

Dentre as causas para o parco número de ocorrências descritas de feições de erosão glacial destacam-se, principalmente: a. a destruição posterior por erosão e pelas atuais condições climáticas que favorecem sobremaneira a ação intempérica; b. a relativamente pequena faixa de exposição de rochas glácio-continentais do Subgrupo Itararé, em parte já erodidas e em parte jazendo sob rochas mais jovens; e c. o desconhecimento destas feições por grande parte dos geólogos.

As feições abrasivas descritas nos trabalhos acima citados foram, em sua maioria, esculpidas sobre rochas do embasamento cristalino ou da Formação Furnas, subjacentes ao Subgrupo Itararé. No presente trabalho, é descrito um pavimento estriado em arenitos do próprio Subgrupo Itararé, aflorante nas proximidades de Engenheiro Maia (Sul do Estado de São Paulo), ao longo das margens e leito do Rio Piritubinha (Fig. 1).

DESCRIÇÃO DO PAVIMENTO Em vários pontos ao longo de cerca de $300 \mathrm{~m}$ do Rio Piritubinha podem ser observadas feições atribuíveis à erosão glacial. A melhor exposição, apresenta uma extenção de cerca de $18 \mathrm{~m}$ de comprimento por $3 \mathrm{~m}$ de largura (Foto 1). As estrias em geral com poucos centímetros de profundidade são contínuas na superfície aflorante, localmente ainda apresentando brilho de polimento (Foto 2), embora já mostre erosão pelas águas do riacho.

Os seixos que ocorrem no pavimento, em porcentagens de $5 \%$ a $10 \%$, em geral são centimétricos, raramente chegando a calhaus com dimensões de cerca de $15 \mathrm{~cm}$ em seu eixo maior. São em grande parte facetados e exibem localmente incipiente orientação paralela às estrias. Apresentam composição ütológica variada, incluindo diversos tipos de quartzitos, sílex, granitos e filitos. Grande parte desses seixos foi retirada por erosão atual, restando apenas os moldes na superfície estriada. Sobre alguns seixos preservados in situ foi verificada a presença de pequenos sulcos lineares paralelos à direção geral das estrias do pavimento.

$\mathrm{O}$ acúmulo de seixos na superfície estriada, a sua orientação e as estrias observadas em sua parte superior sugerem que esta superfície possa constituir, ao mesmo tempo, um pavi- mento de clastos (boulder pavement). Os clastos da base da geleira sofrem um retardamento em seu movimento devido à abrasão com a rocha subjacente. Os seixos transportados logo acima na geleira deslocam-se mais rapidamente, podendo colidir com os da base e formar verdadeiros congestionamentos de seixos que, em conseqüência, depositam-se localmente em maior número.

Embora as estrias sejam feições erosivas que indicam normalmente apenas a direção do movimento do gelo, o sentido desse movimento pode ser determinado a partir de outras evidências, como por exemplo a presença de estrias interrompidas por um seixo à sua frente (Foto 2). Em certos casos é ainda possível verificar uma pequena deformação da rocha à frente do seixo, denotando que este foi empurrado pelo fluxo da geleira contra o sedimento. O sentido desse movimento no local é para $\mathrm{N} 30 \mathrm{~W}$, aproximadamente coincidente com os dados existentes na literatura para a porção nordeste da Bacia do Paraná.

DESCRIÇÃO SEDIMEIMTOLÓGICA O pavimento estriado do Rio Piritubinha ocorre em sedimentitos da porção basal do Subgrupo Itararé, exibindo inclinação relativamente elevada ( 4NE) graças à tectônica local, em que falhamentos, associados ao Alinhamento do Guapiara (Ferreira 1982), provocaram o basculamento de grandes blocos rochosos.

A rocha sobre a qual foi esculpido o pavimento estriado é constituída por um diamictito arenoso aparentemente maciço, com $30 \%$ a $40 \%$ de matriz lamítica e cerca de $5 \%$ de seixos. Texturalmente, corresponde a um arenito médio, mal selecionado, lamítico, levemente conglomerático a conglomeratic(C), com grãos, granules e seixos comumente angulosos e facetados. Os grãos do arcabouço, formando cerca de $60 \%$ a $70 \%$ da rocha, são compostos predominantemente por quartzo, sendo os feldspatos subordinados, e mais raramente fragmentos de rocha e minerais pesados. Os seixos são polimíticos (quartzitos, sílex, gnáisses, granitos, filitos), predominantemente centimétricos e em parte com estrias.

Os sedimentitos sobrepostos ao pavimento estriado são compostos por arenitos mal selecionados, levemente lamíticos e levemente conglomeráticos. A granulometria é variável desde areias muito finas até muito grossas, geralmente subarredondadas, compostas dominantemente por quartzo e mais raramente por feldspatos e fragmentos de rochas. Os grânulos e seixos são comumente subarredondados, menos freqüentemente facetados e de composição litológica variada (quartzitos, filitos, folhemos).

Estas rochas exibem estratificações cruzadas de médio porte, mal definidas, provavelmente devidas à ação de correntes tracionais com elevada carga sedimentar.

CONSIDERAÇÕES FINAIS Estratigraficamente, o pavimento estriado do Rio Piritubinha localiza-se na porção basal do Subgrupo Itararé na área, e é correlacionável aos sedimentitos glaciais encontrados nas proximidades de Sengés (PR), descritos por Caetano-Chang \& Landim (1987).

Embora não tenha sido feita uma análise paleoambiental da 


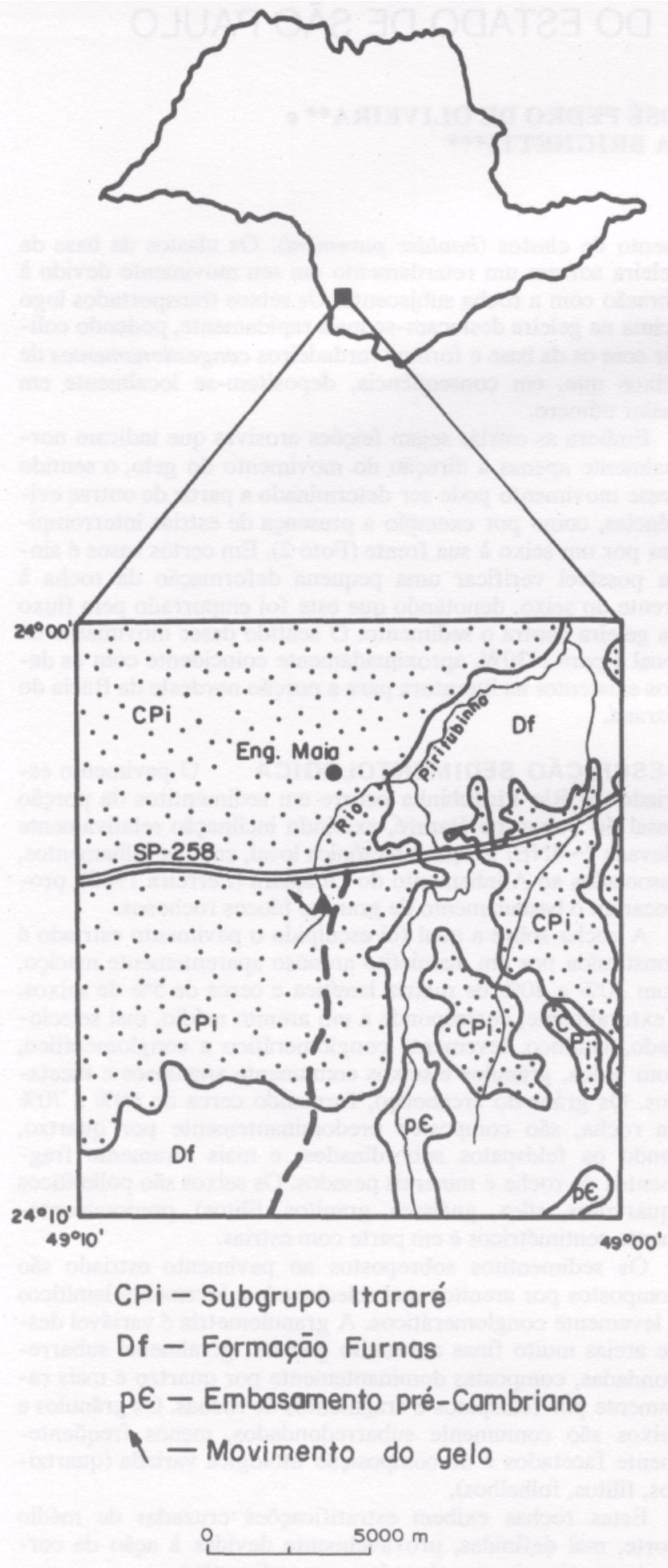

Figura 1 -Localização do pavimento estriado ( $\Delta$ )

Figure 1 -Striated pavement $(\Delta)$ at Piritubinha River

área, é possível, por meio da análise litológica e de estruturas sedimentares dos sedimentitos abaixo e acima do pavimento, aventar-se hipóteses sobre suas origens. Os sedimentitos sotopostos à superfície estriada são diamictitos maciços que provavelmente foram depositados pela própria geleira, constituindo depósitos glaciais sensu stricto. As características dos sedimentitos sobrepostos, por sua vez, fazem supor a deposição de material suprido pelas geleiras, porém retrabalhado

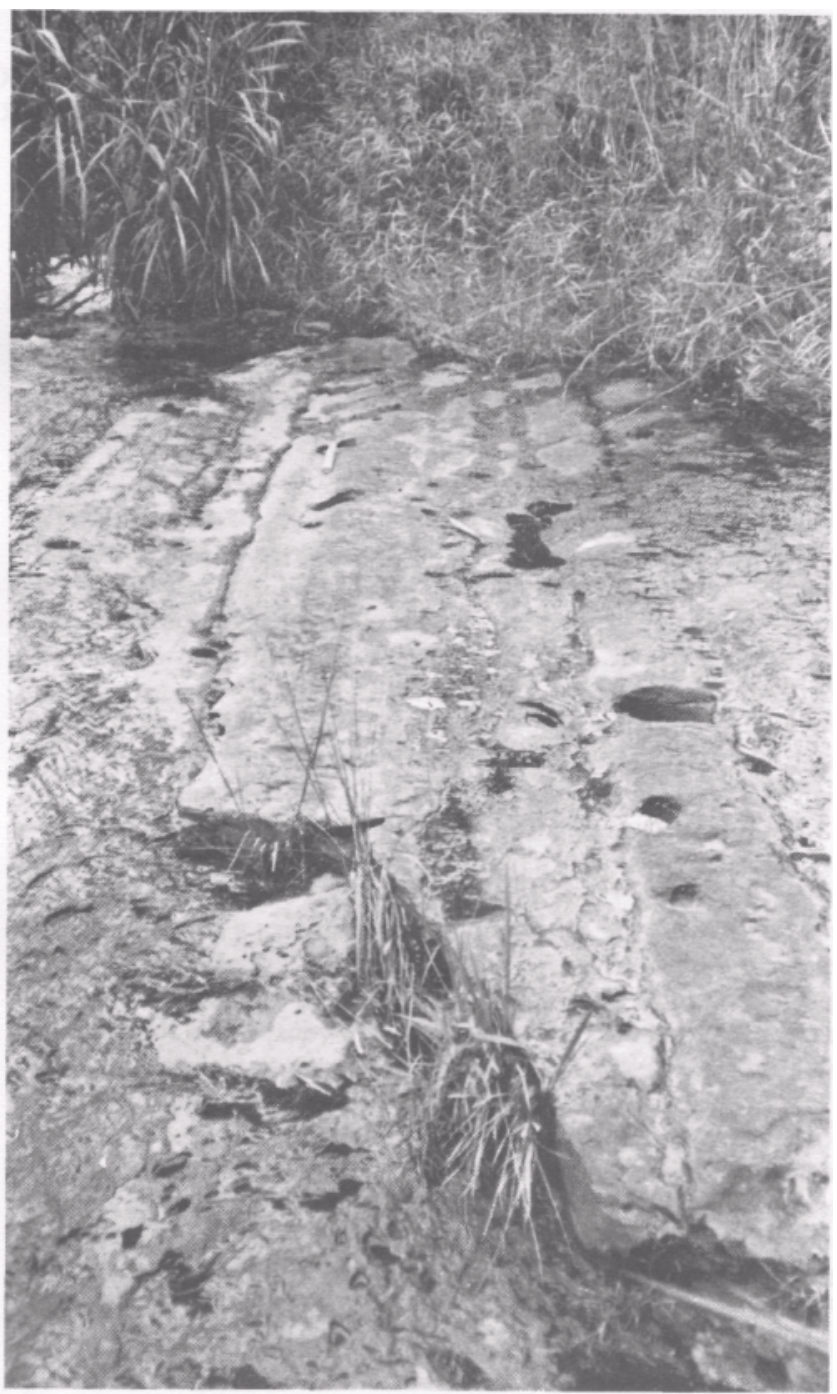

Foto 1 -Vista geral do pavimento estriado Photo 1-General view of the striated pavement

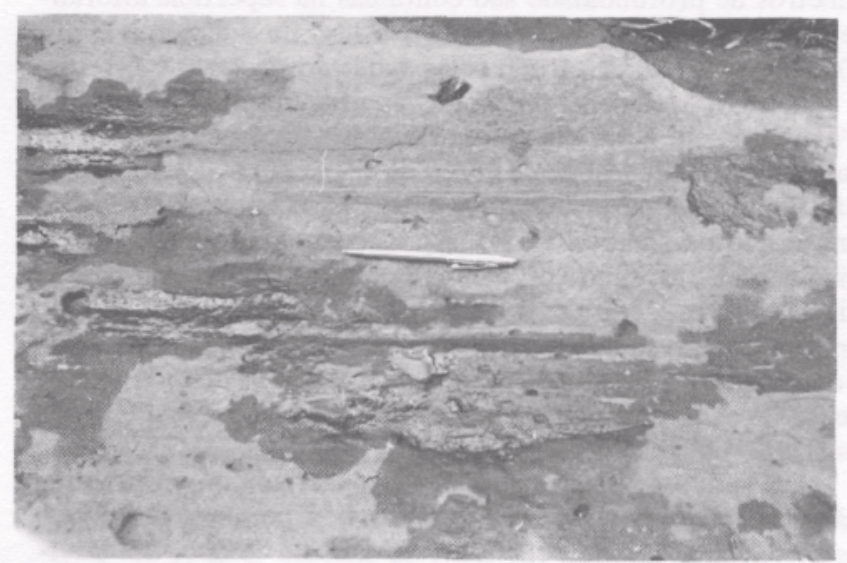

Foto 2 - Detalhe das estrias. Notar, à esquerda na foto, uma esfria terminando em um molde de seixo

Photo 2 - Detailed photograph showing a stria finishing in a gravel mold (at left) 
à sua frente, em leque superior de lavagem glacial (put wash apron), por rios entrelaçados (tipo braided).

A ocorrência desse pavimento estriado vem constituir-se em mais uma evidência da glaciação responsável pela deposi- ção e/ou suprimento dos sedimentitos basais do Subgrupo Itararé ha região sul do Estado de São Paulo. Além disso, o rumo das estrias para N30W vem corroborar os dados existentes na literatura de sentidos de fluxo do gelo para noroeste.

\section{REFERÊNCIAS BIBLIOGRÁFICAS}

ALMEIDA, F.F.M. 1948. A Roche Moutonnée de Salto, Estado de São Paulo. GeolMetal., p. 112-118. (Boi. 5).

AMARAL, S.E. 1965. Nova ocorrência de rochas moutonnée em Salto, SP.BoLSocfras. Geol. 14:71-82.

BIGARELLA, JJ.; SALAMUNI, R.; FUCK, R.A. 1967. Striated surfaces and related features developed by the Gondwana ice sheets (State of Paraná, Brazil). Palaeogeogr. PaJaeocVmatol. Palaeoecol., 3:265-276.

CAETANO-CHANG, M.R.; LANDIM, P.M.B. 1987. Os sedimentos glacials da base do Subgrupo Itararé nas proximidades de Itararé (SP). In: SIMPOSIO SUL-BRASILEIRO DE GEOLOGIA, 3, Curitiba, 1987. Atas... Curitiba, SBG. v. 1, p. 401-412.

FERREIRA, FJ.F. 1982. Alinhamentos estnitunús-magnéticos da região centro-oriental da Bacia do Paraná e seu significado tectonico. In: INST. PESQU. TECNOL. Geologia da Bacia do Paraná - reavaliação da potencialidade e prospectMdade de hidrocarbonetos. São Paulo, IPT. p. 143-166.

MACHADO, L.C.R. 1989. Fades e arcabouço estratigráflco do Grupo Itararé em Alfredo Wagner (SC) - sedimentação periglacial. Ouro Preto. 163 p. (Dissertação de Mestrado, Escola de Minas, UFOP).
ROCHA-CAMPOS, A.C.; FARJALLAT, J.E.S.; YOSHIDA, R.1968. New glacial features of the Upper Paleozoic Itararé Subgroup in the State of São Paulo, Brazil. BolJSocJras.Geol., 12:47-57.

ROCHA-CAMPOS, A.C.; FARJALLAT, J.E.S.; YOSHIDA, R. 1969 Crescentic marks on a Late Paleozoic glacial pavement in southeastern Brazil. GeolJSocjtonMuB., 80:1123-1126.

ROCHA-CAMPOS, A.C.; MACHADO, L.C.R.; SANTOS, P.R.; CANUTO, J.R.; CASTRO, J.C. 1988. Pavimento estriado da glaciacão neopaleozóica, em Alfredo Wagner, Santa Catarina, Bnàl.BoUnst.Geoc.Univ.São Paulo, 19:39-46.

ROCHA-CAMPOS, A.C.; SAAD, A.R.; SANTOS, P.R. 1977. Algumas feições periglaciais do Subgrupo Itararé (Neopaleozoico), no Estado de São Paulo. BoUnst.Geoc.Univ. São Paulo, 8:55-66.

MANUSCRITO NB004

Recebido em 4 de outubro de 1989 Revisão do autor em 21 de maio de 1990 Revisão aceita em 8 de junho de 1990 